\begin{tabular}{|c|c|}
\hline $\begin{array}{c}\text { European Association for the } \\
\text { Development of Renewable Energies,Environment } \\
\text { and Power Quality (EA4EPQ) }\end{array}$ & $\begin{array}{c}\text { International Conference on Renewable Energies and Power Quality } \\
\text { (ICREPQ'12) }\end{array}$ \\
Santiago de Compostela (Spain), 28th to 30th March, 2012
\end{tabular}

\title{
Power Control of a Wind Energy Conversion System based on a Doubly Fed Induction Generator using RST and Sliding Mode Controllers
}

\author{
A.BELABBES ${ }^{1}$, B. HAMANE ${ }^{1}$, M.BOUHAMIDA ${ }^{1}$, A.DRAOU $^{2}$ \\ ${ }^{1}$ Department of Electrical EngineeringL.D.E.E Laboratory, \\ University Mohamed Boudiaf1505BpEl Mnaouer, Oran 31000, Algeria \\ ${ }^{2}$ Department of Electrical Engineering, Hail University, Hail, Saudi Arabia, adraou@ yahoo.com \\ Phone/Fax number: +00213560 022717, e-mail: abdallah.belabbes@gmail.com,hamane.bekhada@live.fr
}

\begin{abstract}
In this paper, a power control study analysis of a wind energy conversion system (WECS) based on a doubly fed induction generator (DFIG) connected to the electric power grid is presented. The main objective of this work is to compare the energy production unit performances by the use of two types of controllers (namely, Polynomial RST and Sliding Mode (SM) Controllers) for the WECS control in terms of instruction tracking and robustness with respect to the wind fluctuation and the impact on the quality of the energy produced. A vector control with stator flux orientation of the DFIG is also presented to control the active and reactive powers between the stator and the network. To show the effectiveness of both control methods performances analysis of the system are analyzed and compared by simulation and results included in this paper.
\end{abstract}

\section{Key words}

Wind energy, DFIG, Vector Control, RST Controller. Sliding Mode Controller

\section{Introduction}

Following the oil price increases in the mid-1970s, fresh interest in wind power developed in much of the Western World was being assisted by the great advances in materials and aerospace and computer technology. Wind power is the conversion of wind energy into a useful form of energy by moving air masses. The movement is caused by temperature and pressure differences in the atmosphere, which are tied to the non-uniformity distribution of solar heat. Moreover, the wind device uses several physical phenomena (aerodynamic, mechanics, electric and thermal) and the mathematics necessary to analyze thoroughly the dynamics are highly complex and requires more research to maintain efficient energy with minimal system cost [1], [2]. Doubly fed induction machine is an electrical three-phase asynchronous machine with wound rotor accessible for control. Since the power handled by the rotor side is proportional to the slip, the energy requires a rotor-side power converter which handles only a small fraction of the overall system power [3]. Within the framework of this work, this paper presents a complete modeling and performance comparison for the control of the WECS at the level of the vector controlled DFIG connected to the network by using both RST and SM Controllers. At first, a three polynomials RST Controller is investigated. This regulator, whose synthesis is purely algebraic, is a sophisticated algorithm based on pole placement method which exploits many numerical resources [4]. Then, a controller based on Sliding Mode method (SMC) is used. This type of controller has proven to be an intriguing method for designing controllers and has been applied in many fields due to its excellent properties, such as insensitivity to certain external disturbance and parameters variation [5]. It can exhibit fast dynamic responses if the switching devices are controlled in a frequent and quick manner.

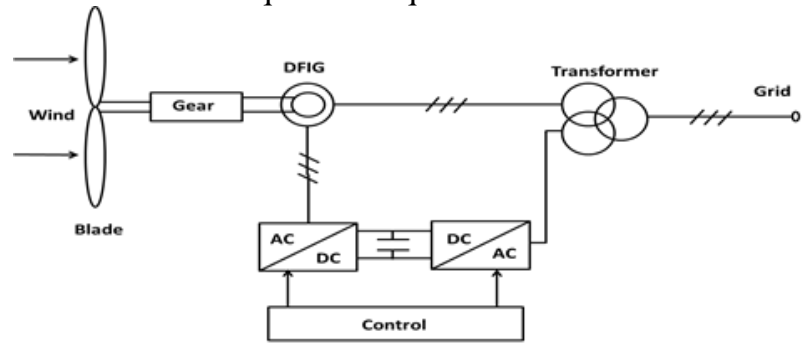

Fig.1. Wind energy conversion system structure

\section{WECS Modeling}

\section{A. Wind turbine model}

The mechanical power transferred from the wind to the aerodynamic rotor is [6]-[14]

$P_{t}=\frac{1}{2} \rho R^{2} V^{3} C_{p}(\lambda, \beta)$

The input torque in the transmission mechanical system is then:

$T_{m}=\frac{P_{t}}{\omega_{t}}=\frac{\frac{1}{2} C_{p}(\lambda, \beta) \rho R^{2} V^{3}}{\omega_{t}}(2)$

Where $\omega_{t}$, is the aerodynamic rotor speed.

The power coefficient can be expressed in terms of the pitch angle $\beta$ and the tip speed ratio $\lambda$ [7]-[14]:

$C_{p}(\lambda, \beta)=c_{1}\left(\frac{c_{2}}{\lambda_{i}}-c_{3} \beta-c_{4}\right) e^{\frac{-c_{5}}{\lambda_{i}}}+c_{6} \lambda$

With: $c_{1}=0.5176, c_{2}=116, c_{3}=0.4, c_{4}=5, c_{5}=21$, $c_{6}=0.0068$

Where $\lambda_{i}$ is given by

$\frac{1}{\lambda_{i}}=\left(\frac{1}{\lambda+0.08 \beta}-\frac{0.035}{\beta^{3}+1}\right)$ 
And the tip speed ratio $\lambda$ is as deduced from [8]-[14]:

$\lambda=\frac{\omega_{t} \cdot R}{v}=\frac{\omega_{r} \cdot G \cdot R}{v}$

\section{B. DFIG model}

In the rotating field reference frame, the model of the wound-rotor induction machine is as shown in Figure2:

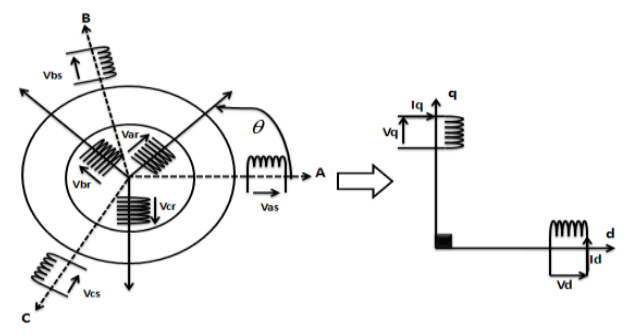

Fig.2.Model of PARK of the DFIG

Equations of stator, rotor voltage and flux components are [9]

$$
\begin{gathered}
\left\{\begin{array}{c}
V_{d s}=R_{s} I_{d s}+\frac{d \varphi_{d s}}{d t}-\omega_{s} \varphi_{q s} \\
V_{q s}=R_{s} I_{q s}+\frac{d \varphi_{q s}}{d t}-\omega_{s} \varphi_{d s} \\
V_{d r}=R_{r} I_{d r}+\frac{d \varphi_{d r}}{d t}-\left(\omega_{s}-\omega_{r}\right) \varphi_{q r} \\
V_{q r}=R_{r} I_{q r}+\frac{d \varphi_{q r}}{d t}-\left(\omega_{s}-\omega_{r}\right) \varphi_{d r}
\end{array}\right. \\
\left\{\begin{array}{l}
\varphi_{d s}=L_{s} I_{d s}+L_{m} I_{d r} \\
\varphi_{q s}=L_{s} I_{q s}+L_{m} I_{q r} \\
\varphi_{d r}=L_{r} I_{d r}+L_{m} I_{d s} \\
\varphi_{q r}=L_{r} I_{q r}+L_{m} I_{q s}
\end{array}\right.
\end{gathered}
$$

Equation of electromagnetic and mechanical torques is [9]: $\left\{\begin{array}{c}T_{e}=-\frac{3}{2} P \frac{L_{m}}{L_{s}}\left(\varphi_{d s} I_{d r}-\varphi_{q s} I_{d s}\right) \\ j \frac{d \Omega_{r}}{d t}+f \Omega_{r}=T_{e}-T_{m}\end{array}\right.$

\section{Control of Active and Reactive Power of DFIG}

Figure 3 shows the control of the active and reactive power of the DFIG:

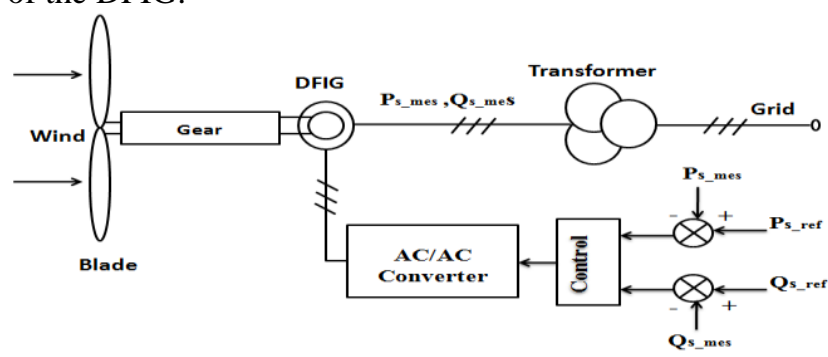

Fig. 3.Control power between the stator and the grid

To achieve a stator active and reactive power vector control as shown on figure 4 , a d-q reference frame synchronized with the stator flux has been chosen [10],[12]. By setting the stator flux vector aligned with daxis. We have $\varphi_{d s}=\varphi_{s}$ and $\varphi_{q s}=0$.

$T_{e}=-\frac{3}{2} P \frac{L_{m}}{L_{s}}\left(\varphi_{d s} I_{d r}\right)$

Note that this torque represents a disturbance for the wind turbine and takes a negative value. The electromagnetic torque and the active power will then depend only on the $\mathrm{q}$-axis rotor current. Neglecting the per phase stator resistance $R_{s}$ (that's the case for medium and high power machines used in wind energy conversion systems)[11], the stator voltages and fluxes can be rewritten as follows:

$\left\{\begin{array}{c}\varphi_{d s}=\varphi_{s}=L_{s} I_{d s}+L_{m} I_{d r} \\ \varphi_{q s}=0=L_{s} I_{q s}+L_{m} I_{q r}\end{array}\right.$

$\left\{V_{d s}=0\right.$

$\left\{V_{q s}=V_{s}=\omega_{s} \varphi_{d s}\right.$

The stator active and reactive power and voltage are given by:

$\left\{\begin{array}{c}P_{s}=V_{d s} I_{d s}+V_{q s} I_{q s}=-V_{s} \\ Q_{s}=V_{q s} I_{d s}-V_{d s} I_{q s}=-V_{s} \frac{L_{m}}{L_{s}}\end{array}\right.$
$\left\{\begin{array}{c}V_{d r}=R_{r} I_{d r}+\left(L_{r}-\frac{L_{m}^{2}}{L_{s}}\right) \frac{d}{d t} I_{d r} \\ \quad-g \omega_{s}\left(L_{r}-\frac{L_{m}^{2}}{L_{s}}\right) I_{q r} \\ V_{q r}=R_{r} I_{q r}+\left(L_{r}-\frac{L_{m}^{2}}{L_{s}}\right) \frac{d}{d t} I_{q r} \\ -g \omega_{s}\left(L_{r}-\frac{L_{m}^{2}}{L_{s}}\right) I_{d r}+g \frac{L_{m} V_{s}}{L_{s}}\end{array}\right.$

In steady state, the second derivative terms in (13) are nil. The third term constitutes cross-coupling terms. The block-diagram representing the internal model of the system is shown in Figure 4. The input blocks relating $V d r$ to $V q r$ represent the simplified rotor converter model. Knowing (12) and (13), it is then possible to synthesize the regulators.

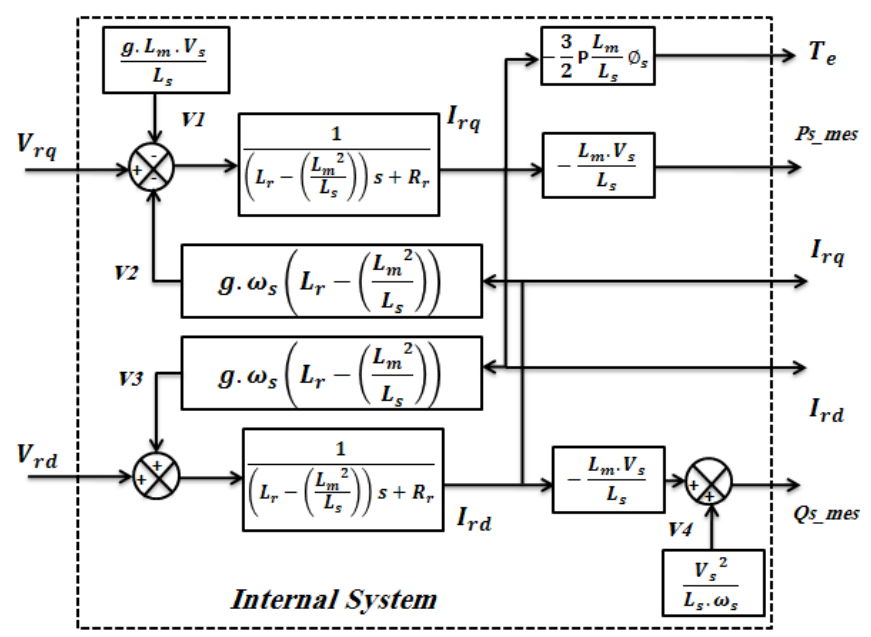

Fig .4.The system power block diagram

\section{Controller Synthesis}

This section deals with the synthesis of the RST and SMC controllers. Both controllers are designed to achieve the following control objectives [9]:

- Performing active and reactive power reference tracking;

- Efficient disturbance rejection ;

- Parametric robustness.

The first objective induces fast dynamics of the transient response but it may lead to few tuning parameters with explicit action on the dynamical response. 
The second objective takes into account the non-linearity and cross-coupling terms. Finally, the last objective is to give parametric insensibility properties to the closed-loop against over-heating and ageing. These objectives are achieved the, the two controllers namely, RST and SM controllers are synthesised.

\section{A. RST Controller design}

The closed-loop system of the RST controller is given by the following block diagram[14]:

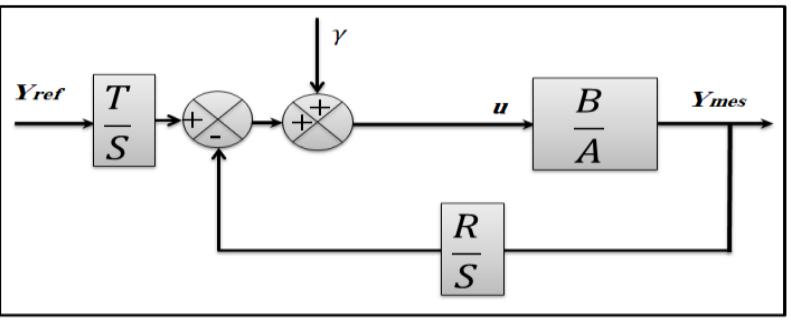

Fog.5. RST Structure

Terms $\boldsymbol{A}$ and $\boldsymbol{B}$ are expressed by:

$\left\{\begin{array}{c}A=L_{s} R_{r}+p L_{s}\left(L_{r}-\frac{L_{m}^{2}}{L_{s}}\right)_{(14)} \\ B=L_{m} V_{s}\end{array}\right.$

The goal of this section to obtain the RST power controller (Active and reactive power), this type of controller is a structure with two degrees of freedom and compared to a one degree of freedom structure. Its main advantage is that it allows the designer to specify performances independently with reference trajectory tracking (reference variation) and with regulation. It is based on the pole placement theory which consists in specifying an arbitrary stability polynomial $\boldsymbol{D}(\boldsymbol{p})$ and calculating $\boldsymbol{S}(\boldsymbol{p})$ and $\boldsymbol{R}(\boldsymbol{p})$ according to the Bezout equation:

$D=A S+B R$

With $\operatorname{deg}(D)=\operatorname{deg}(A)+\operatorname{deg}(S)$.

For the proposed model, we obtain:

$$
\left\{\begin{array}{c}
A=a_{1} p+a_{0} \\
B=b_{0} \\
D=d_{3} p^{3}+d_{2} p^{2}+d_{1} p+d_{0}(16) \\
R=r_{1} s+r_{0} \\
S=s_{2} p^{2}+s_{1} p+d_{0}
\end{array}\right.
$$

According to the robust pole placement strategy, the polynomial $D$ is written as:

$D=\left(s+\frac{1}{T_{c}}\right)\left(s+\frac{1}{T_{f}}\right)^{2}$

With $P_{C}=-1 / T_{C}$ pole of polynomial order $C$ and $P_{f}=$ $-1 / T_{f}$ double pole of the polynomial filter $F$.

$\left\{\begin{array}{c}P_{c}=5 P_{a}=-5 \frac{L_{s} R_{r}}{\left(L_{r} L_{s}-L_{m}^{2}\right)} \\ T_{c}=\frac{1}{P_{c}} \\ T_{f}=\frac{1}{3} T_{c}\end{array}\right.$

To accelerate the system, we adopt the following conditions:

$D=\left(s-5 P_{a}\right)\left(s-15 P_{a}\right)^{2}(19)$
By identifying equations (16) and (19), we deduce the coefficients of polynomial $D$ which are linked to the coefficients of $R$ and $S$ by the Sylvester matrix [4]. Thus, we can determine the parameters of the RST controller as follows:

$$
\left\{\begin{array}{c}
d_{3}=a_{1} s_{2} \rightarrow s_{2}=\frac{d_{3}}{a_{1}} \\
d_{2}=a_{1} s_{1} \rightarrow s_{1}=\frac{d_{2}}{a_{1}} \\
d_{1}=a_{0} s_{1}+b_{0} r_{1} \rightarrow r_{1}=\frac{d_{1}-a_{0} s_{1}}{b_{0}}(20) \\
d_{1}=b_{0} r_{0} \rightarrow r_{0}=\frac{d_{0}}{b_{0}} \\
T=r_{0}
\end{array}\right.
$$

\section{B. Sliding Mode controller design}

The SM controller has been very successful in recent years due to the simplicity of its implementation and its robustness against the uncertainties of the system and external disturbances in the process. Sliding mode control is to bring back the state trajectory to the sliding surface and to advance on it with a certain dynamic point balance [13]-[14]. This trajectory consists of three parts:

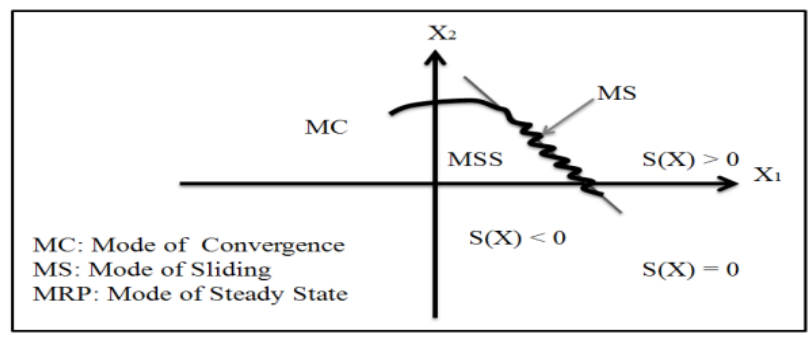

Fig.6.Modetrajectory in the phase plane

1) Choice of the surface of switchgear

For a nonlinear system presented in the following form:

$\left\{\begin{array}{l}\dot{X}=f(X, t)+g(X, t) u(X, t) \\ X \in \Re^{n}, u \in \Re\end{array}\right.$

Where $f(X, t), g(X, t)$ are the two non-linear functions continuous and uncertain assumed bounded. It takes the form of the general equation proposed by J.J.Slotine to determine the slip surface [13]-[14]:

$\left\{\begin{array}{c}S(X)=\left(\frac{d}{d t}+\lambda\right)^{n-1} e \\ e=X^{d}-X\end{array}\right.$

Where $e$ is the size to resolve error, $\lambda$ is positive coefficient, $n$ is order of the system, $X^{d}$ desire greatness: $X^{d}=\left[x^{d}, \dot{x}^{d}, \dddot{x}^{d}, \ldots\right]^{T}, X$ State of the ordered size variable: $X=\left[x, \dot{x}, \ldots, x^{n-1}\right]^{T}$.

\section{2) The convergence condition}

The convergence condition is defined by the equation of Lyapunov [13]-[14] which makes the surface attractive and invariant:

$(S(X))(\dot{S}(X)) \leq 0$

\section{3) Computation of the control}

The control algorithm is defined by the relationship $u=u^{e q}+u^{n}(24)$ 
Where $u$ :Greatness control, $u^{e q}$ : greatness of equivalent command $u^{n}$ : terms of switching control, $\operatorname{sat}(S(X) / \varnothing$ : saturation function, $\varnothing$ : width of the threshold saturation function.

$u^{n}=u^{\max } \operatorname{sat}(S(X) / \varnothing)$

$\operatorname{sat}(S(X) / \emptyset)=\left\{\begin{array}{ll}\operatorname{sign}(s) & s i|s|>\emptyset \\ s / \emptyset & \text { si }|s|<\emptyset\end{array}\right.$ (26) $^{(26)}$

The simplest solution satisfying this condition (Equ.23) has the form:

$\left\{u^{n}=K \operatorname{sign}(S(X))\right.$

$\left\{\begin{array}{l}u^{n} \\ \text { O } 0\end{array}\right.$

\section{$>$ Control of the active power}

To control the active power we take $n=1$, the expression of the control surface of the active power has the form:

$S(P)=\left(P_{s}^{\text {ref }}-P_{s}\right)$

The derivative of the surface is:

$\dot{S}(P)=\left(\dot{P}_{S}^{\text {ref }}-P_{S}\right)$

It replaces the expression of the current (Equ.12).

$\dot{S}(P)=\left(\dot{P}_{s}^{r e f}+V_{s} \frac{L_{m}}{L_{s}} \dot{I}_{q r}\right)$

It takes the current expression $\dot{I}_{q r}$ the voltage equation $V_{q r}$ (Equ.13)

$\dot{S}(P)=\left(\dot{P}_{s}^{\text {ref }}+V_{s} \frac{L_{m}}{L_{s} L_{r} \sigma}\left(V_{q r}-R_{r} I_{q r}\right)\right)$

It replaces the expression of $V_{q r}$ by $V_{q r}^{e q}+V_{q r}^{n}$, the control appears clearly in the following equation: $\dot{S}(P)=\dot{P}_{s}^{r e f}+V_{s} \frac{L_{m}}{L_{s} L_{r} \sigma}\left(\left(V_{q r}{ }^{e q}+V_{q r}{ }^{n}\right)-R_{r} I_{q r}\right)(32)$

During the sliding mode and steady state, we have:

$S(P)=0, \dot{S}(P)=0, V_{q r}^{n}=0$

Which was derived previously, then the greatness of the equivalent command $V_{q r}^{e q}$ can be written as:

$V_{q r}^{e q}=-\dot{P}_{s}^{r e f} \frac{L_{s} L_{r} \sigma}{L_{m} V_{s}}+R_{r} I_{q r}$

With $\sigma=\left(1-\frac{L_{m}^{2}}{L_{s} L_{r}}\right)$

During the convergence mode, the condition for $S(P) \dot{S}(P) \leq 0$ is verified, we set:

$\dot{S}(P)=-V_{s} \frac{L_{m}}{L_{s} L_{r} \sigma} V_{q r}^{n}$

Therefore, the term of switching is given by:

$V_{q r}{ }^{n}=K_{1} \operatorname{sign}(S(P))$

To verify the condition of stability of the system, the $K_{1}$ parameter must be positive. To mitigate any possible exceeding of the reference voltage $V_{q r}$, it is often useful to add a voltage limiter which is expressed by:

$V_{q r}^{l i m}=V_{q r}^{\max } \operatorname{sat}(P)$

\section{Control of the reactive power}

To control the reactive power we take $n=1$, the expression of the control surface of the active power has the form:

$S(Q)=\left(Q_{s}^{r e f}-Q_{s}\right)$

The derivative of the surface is:

$\dot{S}(Q)=\left(\dot{Q}_{s}^{r e f}-Q_{s}\right)$

It replaces the expression of the current (Equ.12).

$\dot{S}(Q)=\left(\dot{Q}_{s}^{r e f}+V_{s} \frac{L_{m}}{L_{s}} \dot{I}_{d r}\right)$

It takes the current expression $\dot{I}_{d r}$ the voltage equation $V_{d r}$ (Equ.13)

$\dot{S}(Q)=\left(\dot{Q}_{s}^{r e f}+V_{s} \frac{L_{m}}{L_{s} L_{r} \sigma}\left(V_{d r}-R_{r} I_{d r}\right)\right)(41)$

It replaces the expression of $V_{d r}$ by $V_{d r}^{e q}+V_{d r}^{n}$, the command appears clearly in the following equation:

$\dot{S}(Q)=\dot{Q}_{s}^{r e f}+V_{s} \frac{L_{m}}{L_{s} L_{r} \sigma}\left(\left(V_{d r}{ }^{e q}+V_{d r}{ }^{n}\right)-R_{r} I_{d r}\right)(42)$

During the sliding mode and steady state, we have:

$S(Q)=0, \dot{S}(Q)=0, V_{d r}^{n}=0$

Which was derived previously, then the greatness of the equivalent control $V_{d r}^{e q}$ can be written as:

$V_{q r}^{e q}=-\dot{Q}_{s}^{r e f} \frac{L_{s} L_{r} \sigma}{L_{m} V_{s}}+R_{r} I_{d r}$

During convergence mode and to allow the condition for $S(Q) \dot{S}(Q) \leq 0$ to be verified, we set:

$\dot{S}(Q)=-V_{s} \frac{L_{m}}{L_{s} L_{r} \sigma} V_{d r}^{n}$

Therefore, the term of switching is given by:

$V_{d r}{ }^{n}=K_{2} \operatorname{sign}(S(Q))$

To verify the condition of stability of the system, the $K_{2}$ parameter must be positive. To mitigate any possible exceeding of the reference voltage $V_{d r}$, it is often useful to add a voltage limiter which is expressed by:

$V_{d r}^{l i m}=V_{d r}^{\max } \operatorname{sat}(Q)$

\section{Simulation Results}

To analyze the system and compare efficiently the two proposed controllers, a set of simulation tests have been performed for $0.5 \mathrm{~s}$, using Matlab/Simulink environment. The PWM inverter on the rotor side of the DFIG is controlled. Both controllers are tested and compared by two different criteria, namely, reference tracking, and robustness by varying the parameters of the system. DFIG and the turbine parameters used in the simulation are listed in table I and II, respectively.

\section{A. Reference tracking}

The machine is first tested as in ideal conditions mode and driven to $1500 \mathrm{rpm}$. Different step inputs for an active and a reactive power were applied and the dynamic responses for both RST and the SM controllers are illustrated in Figure 7. 

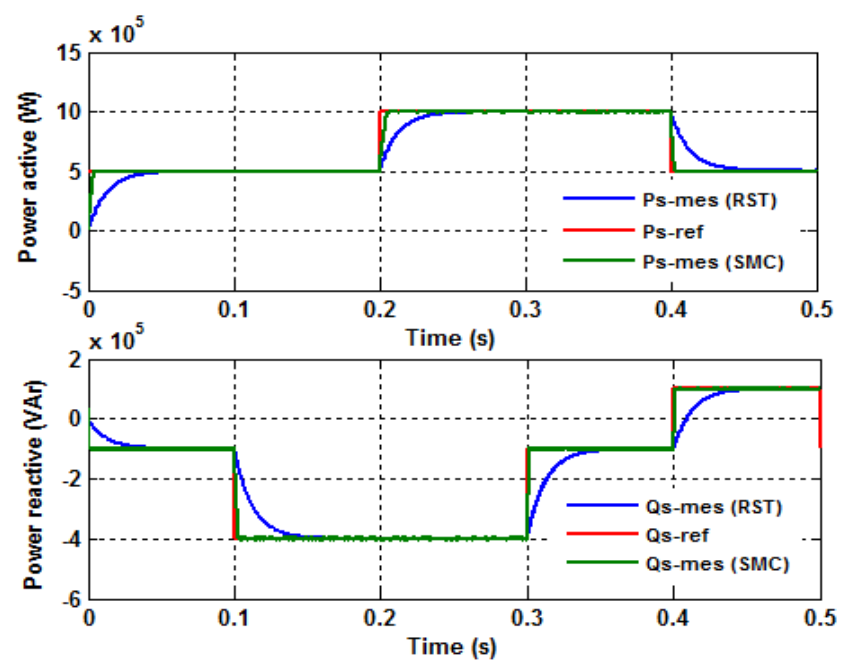

Fig.7. Dynamic Responses to the active and reactive power step change using RST and SMcontrollers

From the simulation results of the active or reactive power dynamics, we note a quicker response for the SM controller, the steps are correctly followed and there is no more error on the powers. The decoupling between the two powers is perfectly respected. The negative sign of the reactive power shows that the generator functions in capacitive mode; for inductive mode the power becomes automatically positive.

\section{B. Robustness}

In order to test the robustness of the SMC, the value of the rotor resistance $R_{r}$ is doubled from its nominal value, the value of stator inductance $L_{s}$ and rotor inductance $L_{r}$ are increased by $10 \%$ of their nominal values and the value of mutual inductance $L_{m}$ is decreased by $10 \%$ of its nominal value. Figure 8,9, 10 and 11, show the effect of parameters variation on the active and reactive power responses for the RST and SM controllers.
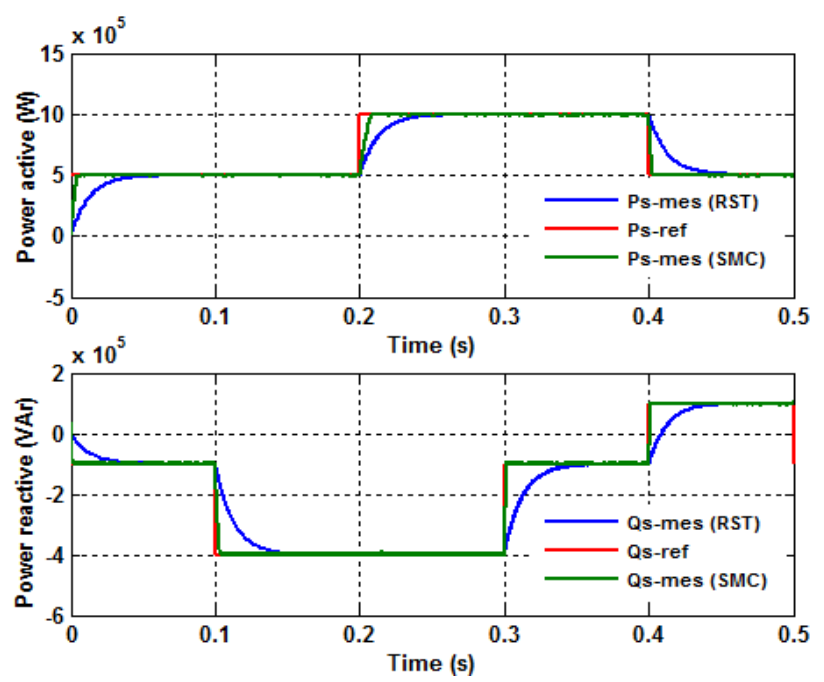

Fig.8.Active and reactive power behavior using RST and SMcontrollers with $R_{r}$ variation
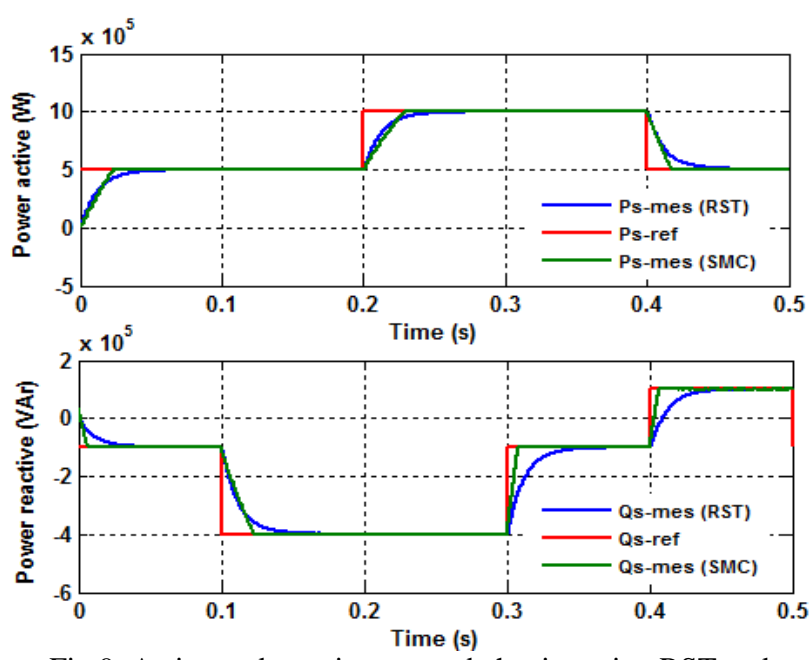

Fig.9. Active and reactive power behavior using RST and
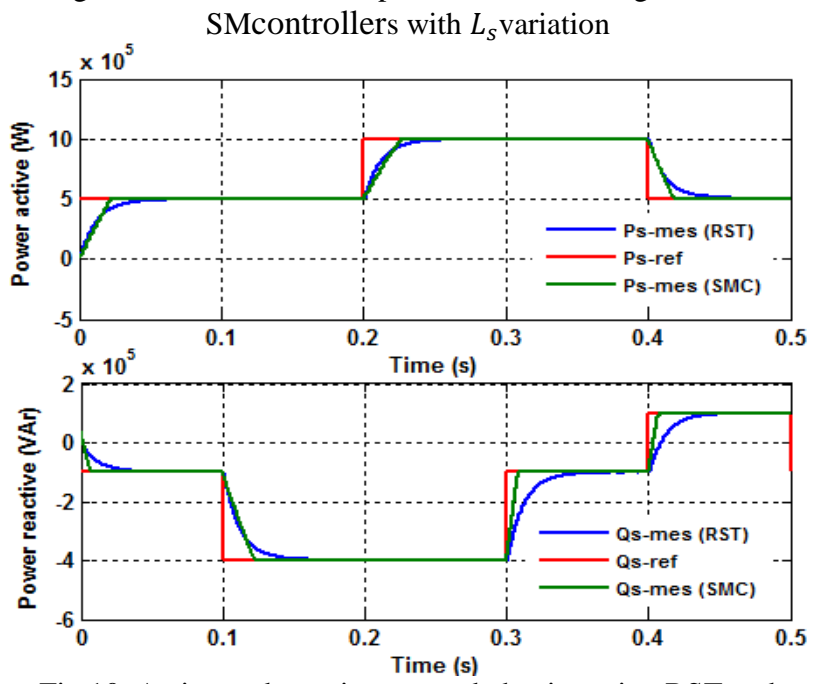

Fig.10. Active and reactive power behavior using RST and SMcontrollers with $L_{r}$ variation
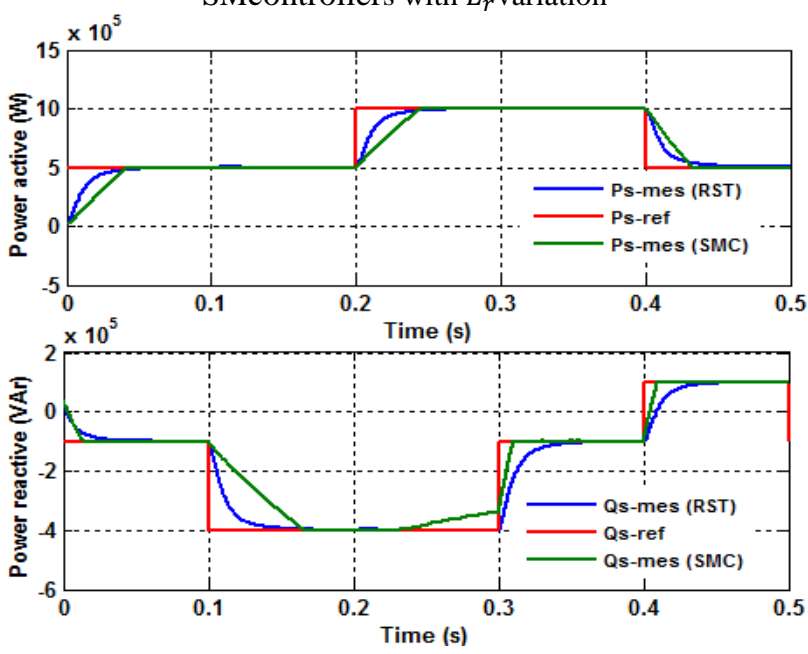

Fig.11. Active and reactive power behavior using RST and SMcontrollers with $L_{m}$ variation

This robustness test shows that in the case of an RST controller, the time response is strongly altered whereas it is almost unmodified when the SMC controller is used.

\section{Comparison of the behavior of the two controllers}

Fig. 12 is included to show the behavioral response of both controllers to the step change of active and reactive power. 

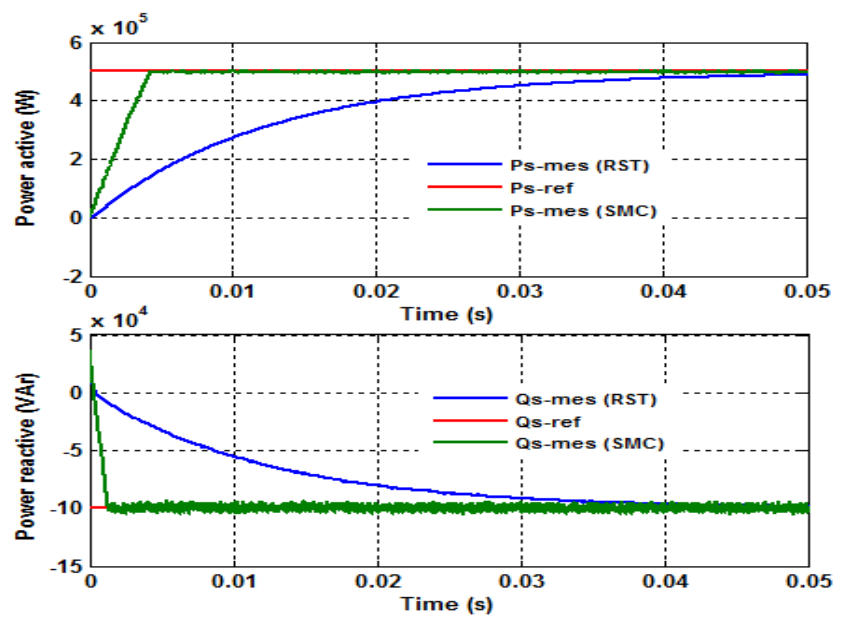

Fig.12. Comparative response of the active and reactive power using the RST and SMcontrollers respectively

Thus we can conclude from these simulation results that the Sliding Mode Controller is more powerful than the RST one.

\section{Conclusion}

In this paper, we have developed a decoupling control method of active and reactive powers for a DFIG. An appropriate model and vector control strategy are first established. Further, two types of controllers using respectively, a RST and SMC controllers are synthesized to perform power reference tracking and efficient disturbance rejection. The results show that, with SMC, the settling time is reduced considerably, peak overshoot of values are limited and oscillations are damped out faster compared to the conventional RST Controller. The transient response provided by the SMC has been best compared to conventional RST Controller.

\section{References}

[1] J.Wen, Y.Zheng, F.Donghan, "A review on reliability assessment for wind power", J. Renewable and Sustainable Energy Reviews 13 (9) (2009) 2485-2494.

[2] M.Hoogwijk, B.de Vries, W.Turkenburg, "Assessment of the global and regional geographical, technical and economic potential of onshore wind energy", J. Energy Economics 26 (5), 2004, pp.889-919.

[3] J.Soltani, A. FarrokhPayam, "A Robust Adaptive SlidingMode Controller for Slip Power Recovery Induction Machine Drives,"IEEETrans.Power Electronics and Motion Control Conference, vol.3, 2006, pp. 3-8,

[4] Fatma HACHICHA, Lotfi KRICHEN," Performance Analysis of a Wind Energy Conversion System based on a Doubly-Fed Induction Generator", IEEE Trans, 8th International Multi-Conference on Systems, Signals \& Devices, 2011, 978-984.

[5] Zhou D, Mu C D, Xu W L. "Adaptive sliding mode guidance of a homing missile", Jur of guidance, control and dynamics, vol. 22, no. 4, , 1999,pp. 589-592.

[6] SiegfriedHeier, 'Grid Integration of Wind Energy Conversion Systems,' John Wiley \& Sons Ltd, ISBN 0-47197143-X, 1998.

[7] H. M. Soloumah and N. C. Kar, "Fuzzy logic based vector control of a doubly-fed induction generator for wind power application," IEEE Trans .WindEngineering, vol. 30, no. 3, pp. 201-224, 2006.
[8] Md. Rabiul Islam1, YouguangGuo, JianGuo Zhu, "Steady State Characteristic Simulation of DFIG for Wind Power System," IEEE Trans. Electrical and Computer Engineering (ICECE), pp. 151-154, 2011.

[9] M. Machmoum, F. Poitiers, C. Darengosse and A. Queric, "Dynamic Performances of a Doubly-fed Induction Machine for a Variable-speed Wind Energy Generation,"IEEE Trans. Power System Technology, vol. 4, Dec. 2002,pp. 2431-2436.

[10] T.D. Mai, B.L. Mai, D.T. Pham, and H.P. Nguyen: "Controlof doubly-fed induction generators using Dspace R\&D controller board - an application of rapid control coordinated with Matlab/Simulink ,“ October 2007, International Symposium on Electrical \& Electronics Engineering, Track. 3, pp 302-307.

[11] L. Zhang, C. Watthansarn and W. Shehered: "A matrix converter excited doubly-fed induction machine as a wind power generator, ", IEEETrans.PowerElectronics and Variable Speed Drives, vol. 2, 06august 2002,pp 532 537.

[12] F. Poitiers M. Machmoum R. Le Daeufiand M.E. aim, "Control of a doubly-fed induction generator for wind energy conversion systems,"IEEE Trans .Renewable Energy, Vol. 3, N. 3, December 2001 pp.373-378.

[13] J.J.Slotine, "Adaptive Sliding controller synthesis fornonlinear systems », IJC, Vol $43 . \mathrm{N}^{\circ} 6,1986$, pp 16311651.

[14] M.Messaouda, A.Ouddane, “ Contrôle Des Puissances Actives et Réactives de la MADA intégrée dans un Système Eolien ", memory for graduation master in automatic department of automatic University Mohamed Boudiaf USTO, June 2011.

\section{Appendix}

Table I. - Parameters of DFIG

\begin{tabular}{|l|l|}
\hline Symbol & Value \\
\hline Rated Power $P_{m}$ & $1.5 \quad \mathrm{MW}$ \\
\hline Stator resistance $R_{s}$ & $0.012 \Omega$ \\
\hline Rotor resistance $R_{r}$ & $0.021 \Omega$ \\
\hline Pole Pairs $P$ & 2 \\
\hline Stator inductance $L_{s}$ & $0.0137 \mathrm{H}$ \\
\hline Rotor inductance $L_{r}$ & $0.0136 \mathrm{H}$ \\
\hline Mutual inductance $L_{m}$ & $0.0135 \mathrm{H}$ \\
\hline The friction coefficient $f$ & $0.0024 \mathrm{~N} . \mathrm{m}_{\mathrm{s}} \mathrm{s}^{-1}$ \\
\hline The moment of inertia $\mathrm{J}$ & $1000 \mathrm{~kg} . \mathrm{m}^{2}$ \\
\hline Slip $g$ & 0.03 \\
\hline The angular speed $\omega_{s}$ & $157 \mathrm{rad} / \mathrm{sec}$ \\
\hline
\end{tabular}

Table II. -Parameters of Turbine

\begin{tabular}{|l|l|}
\hline Symbol & Value \\
\hline Radius of the wind $R$ & $35.25 \mathrm{~m}$ \\
\hline Gain multiplier $G$ & 90 \\
\hline Air density $\rho$ & $1.225 \mathrm{~kg} / \mathrm{m}^{3}$ \\
\hline
\end{tabular}

Table III. -Parameters of Feed

\begin{tabular}{|l|l|}
\hline Symbol & Value \\
\hline Stator rated voltage $V s$ & $398 / 690$ Volt \\
\hline Rated frequency stator $f s$ & $50 \mathrm{~Hz}$ \\
\hline Rotor rated voltage $V r$ & $225 / 389$ Volt \\
\hline Rated frequency stator $f r$ & $14 \mathrm{~Hz}$ \\
\hline
\end{tabular}

Table IV. -Parameters of SMC

\begin{tabular}{|l|l|}
\hline Symbol & Value \\
\hline Gain $K_{1}$ & 500 \\
\hline Gain $K_{2}$ & 150 \\
\hline Value of Saturation & \pm 110 \\
\hline Fixed-step size & $2 \mathrm{e}-5$ \\
\hline
\end{tabular}

